\title{
Evaluation of two different types of attachment systems in midline implant-retained mandibular overdentures
}

\author{
Eman Fathy Rashad Hussien ${ }^{(1)}$, Amany Ahmad Abd El-Fattah ${ }^{(2)}$, Dina Mohmoud Kholief (3)
}

Codex : $56 / 1810$

azhardentj@azhar.edu.eg

http://adjg.journals.ekb.eg

\section{KEYWORDS}

Midline implant, Ball and socket attachment, Magnet attachment, masticatory efficiency, electromyographic activity.

\begin{abstract}
Purpose: was to evaluate the effect of using two different types of overdenture attachment systems (ball and socket and magnet attachments) in single implant retained mandibular overdentures by measuring electromyographic activity and masticatory efficiency of the patient's masseter and temporalis muscles. Materials and methods: Ten completely edentulous patients with ages ranged from 55-65 years. Each patient received overdentures retained by midline implant with two different types of attachments; ball and socket attachment (group A) and magnet attachment (group B). The masticatory efficiency and the electromyographic activity of the masseter and temporalis muscles were evaluated after one month and three months from attachment connection for both groups. Results: The results of this study showed that there were significant decrease in the measurement of masticatory efficiency and electromyographic activity of the masseter and temporalis muscles after one month from using ball and socket attachments. While, there were insignificant differences in the measurements of masticatory efficiency and electromyographic activity of the masseter and temporalis muscles after three months from delivery for both ball and socket and magnet attachments. Conclusion: The masticatory efficiency and electromyographic activity were more improved after using ball and socket attachments compared to magnet attachments.
\end{abstract}

\section{INTRODUCTION}

Retention and stability of complete dentures are important factors in successful restorations of edentulous patients. Improved denture retention and stability facilitate the restorations of oral functions such as mastication and speech and increase patient comfort and selfconfidence. Dental implants have enjoyed great success in edentulous

- Paper extracted from the master thesis entitled Evaluation of two different types of attachment systems in midline implant-retained mandibular overdentures

1. Dentist at Medical Administration, AL-Azhar University.

2. Professor of Removable Prosthodontics, Vice Dean of Faculty of Dental Medicine for Girls, Al-Azhar University.

3. Assistant Professor of Removable Prosthodontics, Faculty of Dental Medicine for Girls, Al-Azhar University 
patients in recent years and significantly improved patient satisfaction and prosthetic outcomes of complete dentures ${ }^{(1,2)}$.

Over the years there has been a strong consensus in dentistry that at least two implants are required to retain a complete denture in the edentulous mandible ${ }^{(3)}$.Indeed, two implants in the interforaminal area have high implant success rates and improve masticatory function ${ }^{(4)}$. The use of a minimal number of implants that is adequate for prosthodontic support and retention is also of economic benefit to the patient ${ }^{(5)}$.Single implantretained overdenture did not differ from two implantretained overdentures in patients satisfaction, but had the distinct of advantages of lower cost, short treatment time and minimal tissue trauma ${ }^{(6)}$. Midline implant-retained mandibular overdenture can be an alternative treatment for the oral rehabilitation of fully edentulous patients, providing greater simplicity and similar retentive strength as compared to two-implant overdentures, improving the user's quality of life ${ }^{(7)}$.

Implant retained mandibular overdentures can be restored with different types of attachments, including bar clip retainers, ball-cap attachments and magnetic attachments. Ball-cap attachments use a spring mechanism to absorb the load forces, which allows even distributions of axial tension and tolerate slight rotation of the denture. This type of attachment design has the advantage of minimizing lateral load on the implant fixture that facilitates bone health ${ }^{(8)}$. Ball attachment is considered the simplest type of attachment for clinical application with tooth or implant supported over- dentures. These attachments don't need a great inter arch space and provide great retention and stability ${ }^{(9)}$.

Magnetic attachment is another design considered useful in single implant-retained dentures because it allows even better load distribution on implant fixture. Magnetic attachment could significantly improve the stability and retention of single implant- retained overdentures ${ }^{(10)}$. It can maintain a constant initial attractive force during maintenance period, it is small in size, easy to install into prostheses and the patient has no difficulty in inserting and removing the denture ${ }^{(11)}$.

Significant improvements in masticatory efficiency can be expected after insertion of a magnetic attachment. As the magnetic attachment does not require a straight insertion path, it has a greater tolerance to implant direction and position. It is also easier to maintain and clean than other attachment types $^{(12)}$.

Masticatory efficiency is the most important indicator for the function of mastication and reflects the functional potential of the dental system that includes the denture. Masticatory efficiency assessment is essential for a comprehensive evaluation of treatment outcomes involving implantretained overdentures. Electromyography is a useful tool to evaluate the behavior of masticatory muscles. It has been used to evaluate muscle alterations after oral rehabilitation with complete denture prosthesis and dental implants ${ }^{(13,14)}$. Several clinical studies have established the patient satisfaction and prosthetic outcomes of two implant-retained overdentures.

The aim of this study was to evaluate the effect of using two different types of overdenture attachment systems (ball and socket and magnet attachments) in single implant retained mandibular overdentures by measuring electromyographic activity and masticatory efficiency of the patient's masseter and temporalis muscles.

\section{MATERIAL AND METHODS}

Ten completely edentulous patients were selected. Patients ages ranged from 55-65 years. All patients were free from any systemic diseases as confirmed by history taking and physical and laboratory examination. Patients with systemic diseases were excluded because they may interfere 
with bone quality, normal healing mechanism, osseointegration of the implants, proper bone response to applied forces and electromyographic muscle activity. Patients' residual ridges were covered with firm mucosa free from any signs of inflammation, ulceration, or flappyness tissue. Six months at least were elapsed from the last extracted tooth before implant placement because bone resorption takes place rapidly in the first months after extraction then progress slowly.

All patients accepted this dental treatment and informed about the steps of this study and signed a written consent with the Research Ethics Committee (REC) approval of the faculty of dental medicine for girls, AL-Azhar University was also obtained.

Cone Beam Computed Tomography (CBCT) was made for each patient. CBCT accurately determines the height and the width of bone and the proximity of the proposed implant placement site to adjacent vital structures. All patients received upper and lower heat cured acrylic resin dentures. The surgical procedure of dental implant placement was made by two-stage technique to minimize the risk of infection, since the peri-implant tissue is allowed to heal separate from the oral microbial environment.

All patients received screw shaped, self-tapping, root form implant, where the threads of the implant allow self-tapping, provide primary fixation of the implant to the bone during the initial healing period as well as increasing the area of contact between

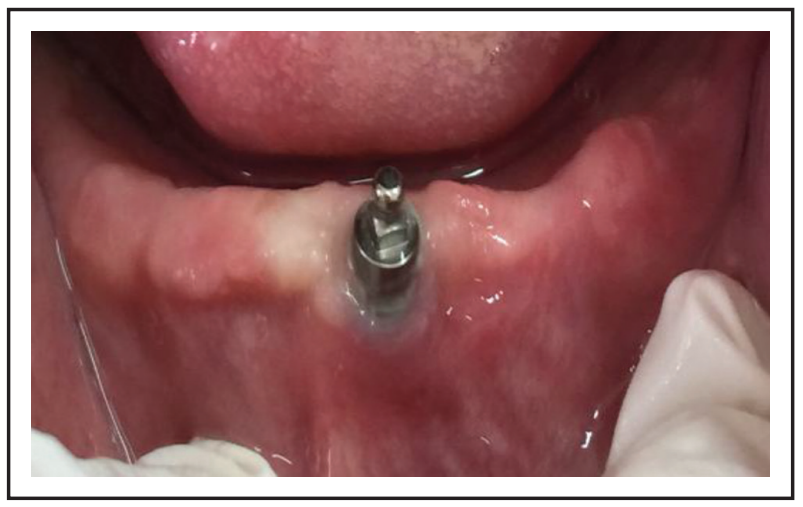

Fig. (1): Ball attachment. the implant and the surrounding bone. The implant is placed in the symphyseal region where favorable bone quality and quantity is usually found.

After three months the patient was recalled for implant evaluation; periapical film was taken for inspection of implant osseointegration. The patients were divided into two groups;

Group I: Five patients received ball and socket attachments then received magnet attachments.

Group II: Another five patients received magnet attachments then received ball and socket attachments.

A healing abutment was placed and remained for seven days to allow gingival tissue healing. After seven days the healing abutment was removed and the ball and socket attachment connected to the implant fixture (Fig 1). Masticatory efficiency and electromyographic activity of masseter and temporalis muscles were evaluated after one month and three months from complete denture delivery. Patients were considered to be as a (Group A).

After testing procedure evaluation the ball and socket abutments and were removed and Magnet abutments were inserted to the implants(Fig 2). Masticatory efficiency and electromyographic activity of masseter and temporalis muscles were evaluated after one month and three months from complete denture delivery. These recrdings were considered to be as a (Group B).

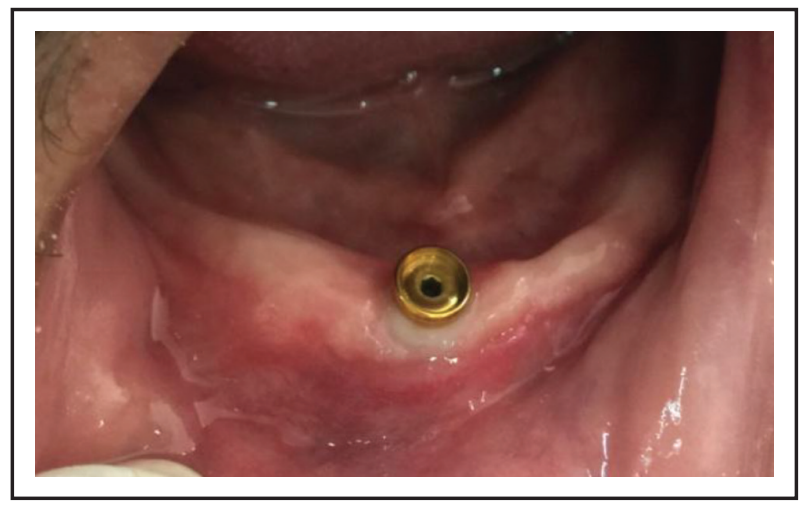

Fig. (2) Magnet attachment. 


\section{Masticatory efficiency test}

The masticatory efficiency was evaluated after one month and after three months from ball and socket and magnet attachments connection while patients were chewing standardized pieces of :

One $\mathrm{cm}$ cube of banana and carrot and one grain of peanuts. These foods represent soft food, hard fibrous food and hard crushable food, respectively. These food items have less variability. The specific characteristics of each food item can influence the use of one food item versus another and also affect masticatory capacity.

Five measurements were recorded during chewing food specimens as follow:

a) The number of chewing strokes up to the first swallow.

b) The number of chewing strokes untill mouth free of food.

c) The number of swallowing untill mouth free of food.

d) The time (in seconds) elapsed until the first swallow.

e) The time (in seconds) elapsed until the mouth was free of food.

Patient was observed and asked about preferred and non-preferred side. Three pieces of each test food were chewed by the patient, and the mean of the three recordings were considered the masticatory efficiency mean for that patient. Masticatory efficiency was selected as the primary variable for sample size determination because of its possible effects on ingestion, dietary intake and social behavior.

The masseter and temporalis muscle were chosen for representing the masticatory muscle activity, since they are the largest and strongest muscle which play a major role in mandibular movement and accessible during recording with surface electrodes.

\section{Electromyographic (EMG) recordings}

The EMG recordings were made after one month and after three months for ball and socket and magnet attachments. EMG recordings were made by computer electromyography based data acquisition system and were expressed as root mean square (RMS).

Recording the electromyographic activity of the masseter and temporalis muscles during chewing carrots, banana and at maximum clinching were made as mentioned before

\section{RESULTS}

All patients sharing in this study were well motivated to complete the follow-up schedule. There were two study groups; Group A for ball and socket attachment, Group B for Magnet attachment.

The masticatory efficiency and the electromyographic activity of the masseter and temporalis muscles were evaluated after one month and three months from attachment connection for both groups.

The results of this study showed that there were significant decrease in the measurement of masticatory efficiency and electromyographic activity of the masseter and temporalis muscles after one month from using ball and socket attachments. While, there were insignificant differences in the measurements of masticatory efficiency and electromyographic activity of the masseter and temporalis muscles after three months from delivery for both ball and socket and magnet attachments. Statistical analysis was tabulated in tables (1-3). 
Table (1): Masticatory efficiency for both groups during chewing (banana, peanut and carrot) after one month.

\begin{tabular}{|c|c|c|c|c|c|c|c|c|c|c|}
\hline & \multicolumn{2}{|c|}{$\mathbf{A}$} & \multicolumn{2}{|c|}{ B } & \multicolumn{2}{|c|}{$\mathrm{C}$} & \multicolumn{2}{|c|}{ D } & \multicolumn{2}{|c|}{$\mathbf{E}$} \\
\hline & GA & GB & GA & GB & GA & GB & GA & GB & GA & GB \\
\hline \multicolumn{11}{|l|}{ Banana } \\
\hline Mean & 15.6 & 19.2 & 15.6 & 19 & 1 & 1 & 13.43 & 17.34 & 13.43 & 17.34 \\
\hline $\mathrm{SD}$ & 2.1 & 2.8 & 2.13 & 2.83 & 0 & 0 & 3.71 & 3.01 & 3.71 & 3.81 \\
\hline $\mathrm{P}$ & \multicolumn{2}{|c|}{$*$} & \multicolumn{2}{|c|}{$*$} & \multicolumn{2}{|c|}{ NS } & \multicolumn{2}{|c|}{ NS } & \multicolumn{2}{|c|}{ NS } \\
\hline \multicolumn{11}{|l|}{ Peanut } \\
\hline Mean & 24.4 & 27.6 & 34.8 & 36.4 & 2 & 2.2 & 20.86 & 24.88 & 28.7 & 32.83 \\
\hline SD & 2.7 & 3.1 & 1.64 & 1.2 & 0 & 0.45 & 2.02 & 4.43 & 1.1 & 3.68 \\
\hline $\mathrm{P}$ & \multicolumn{2}{|c|}{$*$} & \multicolumn{2}{|c|}{$*$} & \multicolumn{2}{|c|}{ NS } & \multicolumn{2}{|c|}{$*$} & \multicolumn{2}{|c|}{$*$} \\
\hline \multicolumn{11}{|l|}{ Carrot } \\
\hline Mean & 26 & 29.2 & 42.4 & 47.2 & 2.6 & 3.2 & 21.29 & 25.74 & 37.45 & 44.2 \\
\hline SD & 24 & 2.8 & 4.28 & 2.77 & 0.55 & 0.45 & 1.75 & 5.35 & 3.93 & 5.81 \\
\hline $\mathrm{P}$ & \multicolumn{2}{|c|}{$*$} & \multicolumn{2}{|c|}{$*$} & \multicolumn{2}{|c|}{ NS } & \multicolumn{2}{|c|}{$*$} & \multicolumn{2}{|c|}{$*$} \\
\hline
\end{tabular}

SD: Standard deviationNS: Non significant.

- GA: Group (A) ball and socket attachment.

- A-The number of chewing strokes up to the first swallow.

- $C$ - The number of swallowing untill mouth free of food.

- E-The time (in second) elapsed until the mouth was free of food.

Table (2): Masticatory efficiency for both groups during chewing (banana, peanut and carrot) after three months.

\begin{tabular}{|c|c|c|c|c|c|c|c|c|c|c|}
\hline & \multicolumn{2}{|c|}{$\mathbf{A}$} & \multicolumn{2}{|c|}{ B } & \multicolumn{2}{|c|}{ C } & \multicolumn{2}{|c|}{ D } & \multicolumn{2}{|c|}{$\mathbf{E}$} \\
\hline & GA & GB & GA & GB & GA & GB & GA & GB & GA & GB \\
\hline \multicolumn{11}{|l|}{ Banana } \\
\hline Mean & 14 & 14.8 & 14 & 14.8 & 1 & 1 & 11.98 & 12.74 & 11.98 & 12.64 \\
\hline $\mathrm{SD}$ & 3.7 & 4 & 3.67 & 3.96 & 0 & 0 & 3.56 & 3.93 & 3.56 & 3.93 \\
\hline $\mathrm{P}$ & \multicolumn{2}{|c|}{$*$} & \multicolumn{2}{|c|}{ NS } & \multicolumn{2}{|c|}{ NS } & \multicolumn{2}{|c|}{$*$} & \multicolumn{2}{|c|}{ NS } \\
\hline \multicolumn{11}{|l|}{ Peanut } \\
\hline Mean & 21.8 & 22 & 28.8 & 29 & 1 & 1.2 & 22.49 & 22.93 & 24.18 & 25.27 \\
\hline $\mathrm{SD}$ & 3.7 & 4.1 & 3.11 & 8.6 & 0 & 0.4 & 3.9 & 3.32 & 2.9 & 5.85 \\
\hline $\mathrm{P}$ & \multicolumn{2}{|c|}{ NS } & \multicolumn{2}{|c|}{ NS } & \multicolumn{2}{|c|}{ NS } & \multicolumn{2}{|c|}{ NS } & \multicolumn{2}{|c|}{ NS } \\
\hline \multicolumn{11}{|l|}{ Carrot } \\
\hline Mean & 29.4 & 30.6 & 35.6 & 36.4 & 2.4 & 2.2 & 23.07 & 23.88 & 32.04 & 33.13 \\
\hline SD & 3 & 8.2 & 5.46 & 4.83 & 0.55 & 0.45 & 1.14 & 6.09 & 3.63 & 6.38 \\
\hline $\mathrm{P}$ & \multicolumn{2}{|c|}{ NS } & \multicolumn{2}{|c|}{ NS } & \multicolumn{2}{|c|}{ NS } & \multicolumn{2}{|c|}{$*$} & \multicolumn{2}{|c|}{ NS } \\
\hline
\end{tabular}

\section{SD: Standard deviation $\quad$ NS: Non significant.}

- GA: Group (A) ball and socket attachment.

*. Significant.

- GB: Group (B) magnet attachment.

-A-The number of chewing strokes up to the first swallow. $\bullet B$ - The number of chewing strokes untill mouth free of food.

- $C$ - The number of swallowing untill mouth free of food. $\quad$ D-The time (in second) elapsed until the first swallow.

- E-The time (in second) elapsed until the mouth was free of food. 
Table (3) Comparison of EMG of Masseter and Temporalis muscle in both groups.

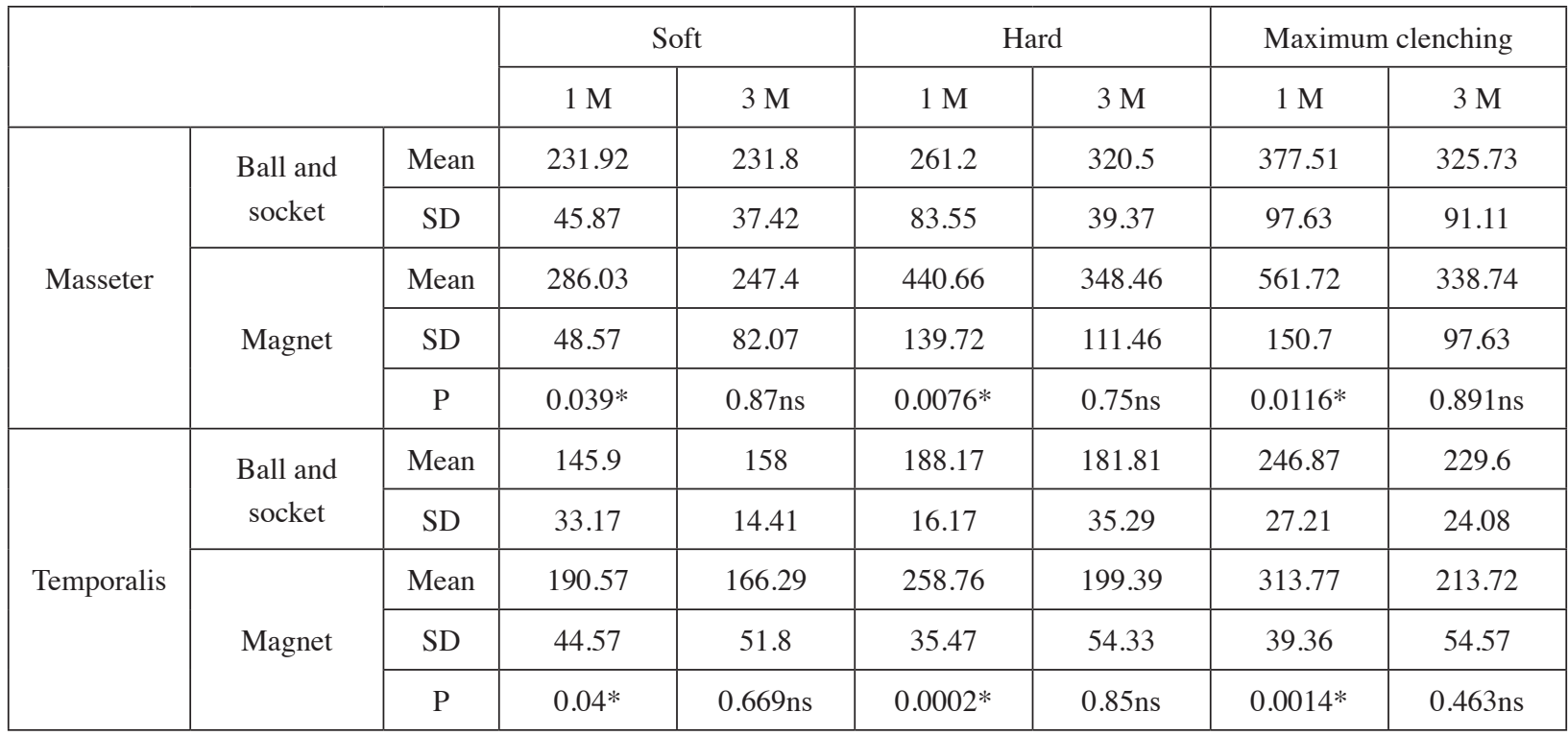

SD: Standard deviationNS: Non significant.

*: Significant.

\section{DISCUSSION}

This study was done to evaluate the effect of using ball and socket and magnet attachments in midline implant retained mandibular overdenture on the masticatory efficiency and muscle activity.

The results of this study showed that there was significant decrease in the measurement of masticatory efficiency after one month from using ball and socket attachments during chewing of the three test foods compared to that of magnet attachment. The patients performed a less number of chewing strokes both until first swallow and until mouth empty of food, also decrease in the time elapsed until first swallow and until mouth empty of food. This indicates improvement in the masticatory function after one month from delivery in dentures retained by ball and socket attachment (group I) than magnet attachment (group II) this could be attributed to the fact that the retention obtained by ball and socket attachments might be considered as a treatment of choice for patients who need more retention and stability of complete dentures compared to the vertical attraction of the magnet attachments with poor lateral retention and stability ${ }^{(9)}$.

However, after three months of denture delivery this study showed no significant difference in the number of swallow until mouth empty of food was evident in the first group during chewing of the three test foods. This may indicates that the number of swallows until mouth empty is less sensitive in distinguishing the masticatory efficiency than the number of strokes. The significant difference in masticatory efficiency measurement between the two studied groups, ball and socket and magnet attachments groups may be due to the improvement of oral function depends on the degree of retention and stability of the denture and thus on the type of attachment $^{(15)}$.

On the other hand, there were insignificant differences in the measurements of masticatory efficiency after three months from delivery for both ball and socket and magnet attachments or between the two studied groups. This findings could be explained on the basis of the neuromuscular adaptation to new denture was proved to be 
achieved after three months wearing period, so the patients had the same numbers of chewing strokes, numbers of swallows and needed the same time for swallowing, therefore no change was found after three months between two groups ${ }^{(16)}$.

These findings were in agreement with the results of many previous studies that reported that the treatment with implants and attachments was provided of neuromuscular adaptation towards values of healthy dentate. Regardless of the type of prosthesis, patients usually function with their prosthesis much better after three months and they become experienced in dealing with it functionally ${ }^{(16)}$.

The results of this study showed that there were significant differences in the mean muscle activity between the two studied groups, ball and socket and magnet groups, after one month dentures use. This may be due to the RMS is the effective value of an electrical signal which is equal to the total power of the signal. This power is dissipated in two forms, mechanical energy in the form of action done (chewing) and electrical energy. The improvement in the denture retention by attachments was compensated in the mechanical part of the energy as demonstrated by better masticatory function. The treatment with implant overdenture retained by ball and socket attachment improved the functional state of the masticatory apparatus and aided in establishment of better neuromuscular coordination by improving retention, support, and stability of the prosthesis, and, consequently, less effort had to be exerted by the muscles to control the prosthesis during function ${ }^{(17)}$.

On the other hand, there were insignificant differences in the mean values of muscle activity after three months between the two studied groups of dentures use. This could be attributed to the fact that neuromuscular adaptation to new denture was proved to be achieved after three months wearing period, so the effort exert by the masticatory muscle had been reduced gradually recording lesser values of EMG at three months from prosthesis insertion ${ }^{(18)}$.

\section{CONCLUSION}

Within the limitation of this study, it could be concluded that:

- The masticatory efficiency and electromyographic activity were improved after using both ball and socket attachments and magnet attachments. However, complete overdentures retained with ball and socket attachment showed higher masticatory performance compared to those retained by magnet attachment.

- A single midline implant retained mandibular overdenture con be considered as a suitable and cost-effective treatment option for completely edentulous patients and enhance the masticatory efficiency.

\section{REFERENCES}

1. Turkyilmaz I, Company AM, McGlumphy EA. Should edentulous patients be constrained to removable complete dentures?. The use of dental implants to improve the quality of life for edentulous patients. Gerodontology. 2010;27:3-10.

2. Feine js, Carlsson GE, Awad MA. The McGill consensus statement on overdentures. Mandibular two-implant overdentures as first choice standard of care for edentulous patients. Gerodontology. $2002 ; 19: 3-4$

3. Thomason JM, Feine J, Exley C. Mandibular two implantsupported overdentures as the first choice standard of care for edentulous patients .Br Dent. 2009; 207:185-186.

4. Kronstrom M, Davis B, Loney R, Hollender L. A prospective randomized study on the immediate loading of mandibular overdentures supported by one or two implants: a 12- month follow-up report . Int $\mathrm{J}$ Oral Maxillofac Implants. 2010 ; 25:181-188.

5. Celik G, Uludag B. Photoelastic stress analysis of various retention mechanisms on 3- implant-retained mandibular overdentures. J Prosthet Dent.2007;97:229-235.

6. Walton JN, Glick N, Macentee MI. A randomized clinical trial comparing patient satisfaction and prosthetic 
outcomes with mandibular overdentures retained by one or two implants. Int J Prosthodont. 2009;22:331-339.

7. Mattia P R, Botega DM, Zani SR. Evaluation of retentive force of attachment systems for overdentures retained by one or two implants. Stomatos. 2016;22: 15-22.

8. Alqutaibi AY, Kaddah AF. Attachments used with implant supported overdenture. Int Dent Med J Adv Res. 2016; 2:1-5.

9. Muhamed A, Georges C, Azzaldeen A. implant-supported overdentures: clinical review. IEJPDCR. 2017; 6:403-411.

10. Sadig W. A comparative in vitro study on the retention and stability of implant- supported overdentures. Quintessence Int. 2009; 40:313-319.

11. Khoo HD, Chai J, Chow TW. Prosthetic outcome, patient complaints, and nutritional effects on elderly patients with magnet-retained, implant-supported overdentures-a 1- year report. Int J Oral Maxillofac Implants. 2013; 28: 1278-1285.

12. Maeda Y, Horisaka M, Yagi K. Biomechanical rationale for a single implant-retained mandibular overdenture: an in vitrostudy. Clin Oral Implants Res . 2008 ;19:271-725.

13. Rashid F, Awad MA, Thomason JM. The effectiveness of 2-implant overdentures-a pragmatic international multicentre study. J Oral Rehabil. 2011 ;38:176-184.

14.Van der Bilt A, Burgers M, van Kampen FMC. Mandibular implant supported overdentures and oral function. Clin Oral Implants Res 2010; 21:1209-1713.

15. Elsyad MA, Hegazy SA, Hammouda NI, Al-TonbaryGY, Habib AA. Chewing efficiency and electromyographic activity of masseter muscle with three designs of implantsupported mandibular overdentures. A cross-over study Clin. Oral Impl. Res. 2014;25: 742-748.

16. Ucankale M, Akoglu B, Ozkan Y, Kulak Y. The effect of different attachment systems with implant-retained overdentures on maximum bite force and EMG. The Gerodontol . 2012 ;29:24-29.

17. Ibraheem EMA and Nassani MZ. The effect of flexible acrylic resin on masticatory muscle activity in implantsupported mandibular overdentures: a controlled clinical trial. Electron Physician. 2016; 8: 1752-1758.

18. Uçankale M, Akoğlu B, Ozkan Y and Ozkan YK. The effect of different attachment systems with implantretained overdentures on maximum bite force and EMG. Gerodontol. 2012; 29:24-29. 